\title{
Performance Comparison of Routing Protocols in Mobile Ad Hoc NeTWORKS
}

\author{
Mohamed Elboukhari ${ }^{1}$, Mostafa Azizi ${ }^{1}$ and Abdelmalek Azizi ${ }^{2,3}$ \\ ${ }^{1}$ Department of Applied Engineering, ESTO, Oujda, Morocco \\ ${ }^{2}$ Departement Mathematics \& Computer Science, FSO, Oujda, Morocco \\ ${ }^{3}$ Academy Hassan II of Sciences \& Technology, Rabat, Morocco
}

\begin{abstract}
Routing protocols have an important role in any Mobile Ad Hoc Network (MANET). Researchers have elaborated several routing protocols that possess different performance levels. In this paper we give a performance evaluation of AODV, DSR, DSDV, OLSR and DYMO routing protocols in Mobile Ad Hoc Networks (MANETS) to determine the best in different scenarios. We analyse these MANET routing protocols by using NS-2 simulator. We specify how the Number of Nodes parameter influences their performance. In this study, performance is calculated in terms of Packet Delivery Ratio, Average End to End Delay, Normalised Routing Load and Average Throughput.
\end{abstract}

\section{KEYWORDS}

Mobile Ad Hoc Networks (MANETs), Performance Comparaison, AODV, DSR, DSDV, OLSR, DYMO.

\section{INTRODUCTION}

Actually Mobile Ad Hoc Network (MANET) is very used. A network of type MANET is a group of mobile stations sharing a radio transmission and they do not have any fixed centralized administration. MANET operates in a dynamic topology. Each station possesses limited resources such as processing power and battery. Mobile stations in MANET exchanges messages with each other in a multi-hop manner. Hence, a station transmits a packet to a destination to another node through intermediate mobile stations and each station may operate as an end point and also can operate as a router.

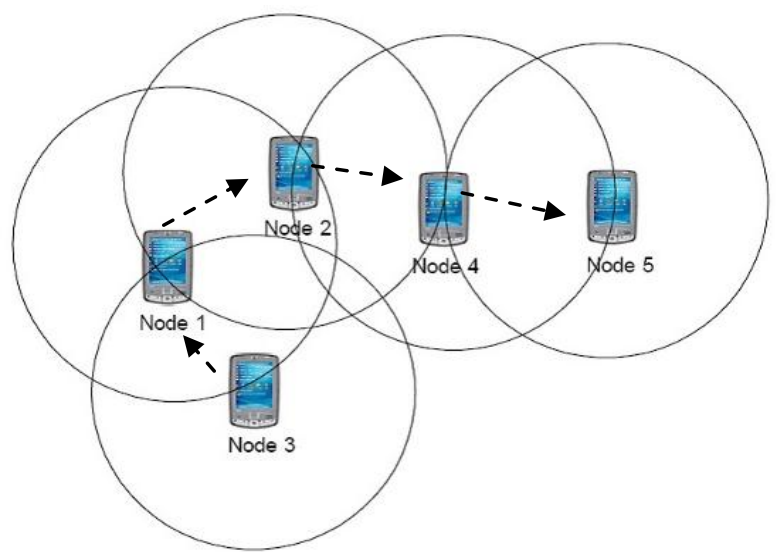

Figure 1. Mobile stations operate in MANET as routers 
many work has been elaborated in the design of routing protocols in different kinds of ad hoc networks like MANETs (Mobile Ad Hoc Networks), VANETS (Vehicular Ad-Hoc Networks), WSNs (Wireless Sensor Networks), and WMNs (Wireless Mesh Networks) etc. [1]. Implementing the routing protocols is the main goal of the MANETs. For such implementations concepts of game-theoretic approach, dynamic control approach, information-theoretic approach, or ad hoc networks routing-based approach has been applied [2].

a station in MANETs can exchanges messages with other mobile stations whether they are in the same wireless channel or not. so, four essential functions are to be designed by the routing protocols: channel assignment, packet routing, network topology, scheduling and maintaining network connectivity. Routing protocols in MANETs are implemented with some basic objectives that are minimum control overhead, dynamic topology maintenance, multi-hop routing, loop prevention and minimum processing overhead [3].

The remainder of the article is organized as follows. We describe the related works in section 2, in section 3 we give a presentation of MANET routing protocols. In section 4, we describes simulation environment. The results of our simulation are analysed in section 5. Finally, in section 6 we conclude the paper.

\section{RELATED WORKS}

Several works have been done concerning the performance evaluation of many MANET routing protocols. We focus on those works performed by network simulator NS-2[4].

Table 1 shows that comparative performance evaluation for all the parameters namely Packet Delivery Ratio, Throughput, Average End to End Delay, Jitter, Routing Load, and Routing Frequency among the routing protocols have not been done in a single paper.

Table 1. Performance analysis of MANET routing protocols.

\begin{tabular}{|c|c|c|c|}
\hline $\begin{array}{l}\text { Ref. } \\
\text { no }\end{array}$ & Protocols used & Performance metrics & Variable Parameters \\
\hline [5] & $\begin{array}{l}\text { AODV, DSR, } \\
\text { DSDV }\end{array}$ & $\begin{array}{l}\text { End to End Delay, Packet Delivery Ratio, } \\
\text { Normalized routing load, Throughput }\end{array}$ & Mobility \\
\hline [6] & $\begin{array}{l}\text { AODV, DSR, } \\
\text { DSDV }\end{array}$ & $\begin{array}{l}\text { End to End Delay, Packet Delivery Ratio, } \\
\text { Throughput }\end{array}$ & Number of nodes \\
\hline [7] & $\begin{array}{l}\text { AODV, DSR, } \\
\text { DSDV }\end{array}$ & $\begin{array}{l}\text { Packet Delivery Ratio, End to End Delay, } \\
\text { Normalized Routing Load }\end{array}$ & $\begin{array}{l}\text { Pause time, Mobility and } \\
\text { Sending rate }\end{array}$ \\
\hline [8] & $\begin{array}{l}\text { AODV, DSR, } \\
\text { DSDV }\end{array}$ & $\begin{array}{l}\text { Average End to End Delay, Normalized } \\
\text { Routing Load, Packet Delivery Ratio, }\end{array}$ & $\begin{array}{l}\text { Number of Nodes, } \\
\text { Speed, Pause time, } \\
\text { Transmission Power }\end{array}$ \\
\hline [9] & $\begin{array}{l}\text { DSDV, AODV, } \\
\text { DSR, TORA }\end{array}$ & $\begin{array}{l}\text { Throughput, Routing Overhead, Path } \\
\text { Optimality, Packet Loss, Average delay }\end{array}$ & $\begin{array}{l}\text { Traffic Load, Movement } \\
\text { patterns }\end{array}$ \\
\hline$[10]$ & $\begin{array}{l}\text { AODV, DSR, } \\
\text { DSDV }\end{array}$ & $\begin{array}{l}\text { Packet Delivery Ratio, Average End to } \\
\text { End Delay, Routing Overhead }\end{array}$ & Pause time \\
\hline$[11]$ & $\begin{array}{l}\text { AODV, DSR, } \\
\text { DSDV }\end{array}$ & $\begin{array}{l}\text { Packet Delivery Ratio, Average End to } \\
\text { End Delay, Normalized Routing Load }\end{array}$ & $\begin{array}{l}\text { Pause time, Number of } \\
\text { nodes and mobility }\end{array}$ \\
\hline [12] & $\begin{array}{l}\text { DSDV, AODV, } \\
\text { DSR, TORA }\end{array}$ & $\begin{array}{l}\text { Average Delay,Jitter, Routing Load, Loss } \\
\text { Ratio, Throughput and Connectivity }\end{array}$ & Network size \\
\hline$[13]$ & DSDV, AODV & $\begin{array}{l}\text { Packet Delivery Fraction, Average End to } \\
\text { End Delay, Throughput }\end{array}$ & $\begin{array}{l}\text { Number on nodes, } \\
\text { Speed, Time }\end{array}$ \\
\hline$[14]$ & AODV, DSDV & $\begin{array}{l}\text { Packet Delivery Ratio, Average End to } \\
\text { End Delay }\end{array}$ & Mobility of nodes \\
\hline
\end{tabular}


In our article, we will compare five MANET protocols (AODV, DSR, DSDV, OLSR, and DYMO). There is no work in our knowledge in the literature which deals with these five MANET routing protocols by considering the variation of Number of Nodes parameter.

\section{Routing Protocols in MANET}

The MANET routing protocols are divided into three classifications depending to their performance and functionality: Table-driven (Proactive) routing protocols, On-demand (Reactive) routing protocols and Hybrid routing protocols [15].

Proactive Routing Protocols: The routing data in these MANET protocols is organised in tables stored by each station. The tables must be updated because the network topology is changing dynamically. These protocols are employed where the route requirements are frequent. FSR, STAR, GSR, DSDV, OLSR, CGSR and WRP are the examples.

Reactive Routing Protocols: These routing protocols choose routes to other stations only when they are needed. A route discovery process is lunched when a station wants to communicate with another station for which it does not possess any route table access. AODV, DSR, LAR, TORA, CBRP and ARA are the examples.

Hybrid Routing Protocols: These MANET protocols employ functionality of both the reactive and proactive protocols. For illustration, proactive protocols could be employed between networks and reactive protocols inside the networks. DST, ZRP, DDR, ZHLS are the examples.

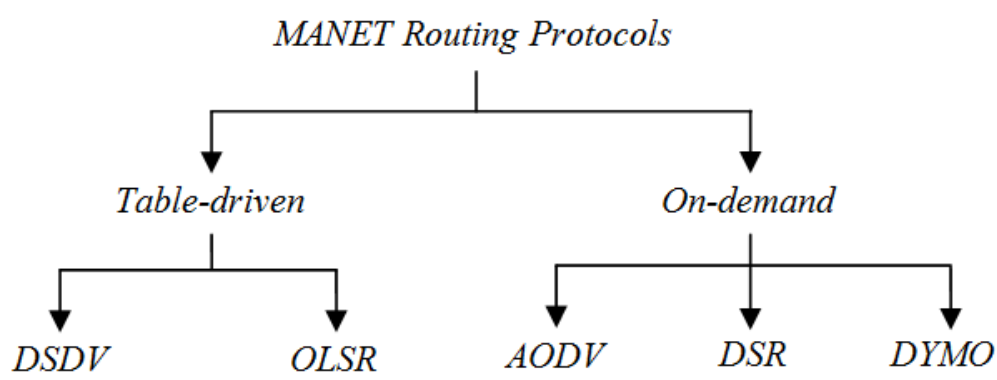

Figure 2. Examples of MANET Routing Protocols

\subsection{Ad-hoc On-Demand distance Vector routing protocol (AODV)}

AODV $[16,17]$ is a MANET routing protocol which employs an on-demand approach to find routes, that is, a route is discovered only when it is needed by a source statin. AODV uses sequence numbers to make certain freshness of routes. AODV employs route request (RREQ) packets broadcasted through the group of connections to discover the paths needed by a source station. it allows stations to find routes very fast for new destinations, and does not need stations to store routes to destinations which are not moving. AODV aids stations to operate in response to an alteration in network topology and link breakages quickly and the AODV operation is loopfree [18]. When a route to a new station is demanded, the source broadcasts a RREQ packet to discover a route to the needed destination. A transitional station that captures a RREQ replies to it using a route reply packet only if it has a route to the destination station whose analogous destination sequence number is greater or equal to the one presented in the RREQ packet. Another important point to mention is that the RREQ also contains the most recent sequence number for the destination of which the source node is responsive. A station capturing the RREQ packet can transmit a route reply (RREP) packet if it is either the destination station or if it 
possesses a route to the destination station with equivalent sequence number greater than or equal to that appeared in the RREQ packet. In this case, it sends (unicasts) a RREP reverse to the source station. Otherwise, it rebroadcasts the RREQ message. Nodes store track of the RREQ's source IP address and broadcast ID.

\subsection{Dynamic Source Routing (DSR)}

Dynamic Source Routing (DSR) [19] is a wireless mesh networks routing protocol. Its implementation is based on a method named "source routing". DSR aids the network to be completely self-configuring and self-organizing.

The Dynamic Source Routing protocol possesses two main mechanisms route discovery and route maintenance. In the route discovery process a source node wishing to drive a packet to a destination node, as certain a source route to the destination. In route maintenance process a station which wants to send a message to a destination is capable to perceive, while employing a source route to the destination, if the network topology has changed such that it can no longer make use of its route to destination station. In case when Route Maintenance shows a source route is no longer work, source station can try to employ any other route, or it can lunch route discovery mechanism again to determine a new route for subsequent packets to destination station.

\subsection{Dynamic MANET On-Demand Routing Protocol (DYMO)}

DYMO [20] uses large variety of mobility patterns by finding dynamically routes on-demand. It also manages a wide selection of traffic patterns. The fundamental functionality of DYMO are route discovery and route maintenance.

In the route discovery, a DYMO router lunches a Route Request packet (RREQ) to find a route to a destination station. During the hop-by-hop broadcasting mechanism, each intermediate DYMO router receiving the RREQ packet stores a route to the originator station. When the target's DYMO router captures the RREQ packet, it stores a route to the originator station and unicasts using a Route Reply (RREP) hop-by-hop through the originating DYMO router. Each transitional DYMO router that captures the RREP packet prepares a route to the target station, and then the RREP packet is unicast hop-by-hop through the originator. When the originator's DYMO router receives finally the RREP packet, routes have been established between the the target DYMO router and originating DYMO router in two directions. Route maintenance is composed of two operations. To maintain routes in use, DYMO routers increase life of route upon successfully forwarding a packet. To operate in response to the modifications in network topology, DYMO routers monitor traffic being forwarded. When a packet is received to be forwarded and a route for the destination station is not determined or the route is broken down, hence the DYMO router of the source station of the packet is notified. A Route Error (RERR) is transmitted to point out the route to one or more disrupted destination addresses is misplaced or broken. When the source's DYMO router captures the RERR packet, it considers the route as broken. Before the DYMO router can forward a message to the same destination station, it must lunch the route discovery again for the destination station.

\subsection{Destination Sequenced Distance Vector (DSDV) Protocol}

DSDV [21] is one of the examples of proactive protocol. DSDV adds a new parameter, sequence number, to each route table at each station. Each node maintains a routing table at its own and which aids in packet transmission. 
For the transmission of packets each node stores routing table. The routing possesses the data for the connectivity to many nodes. These nodes provide all the number of stations (hops) and the available destinations needed to obtain each destination station in the routing table. The routing entry is tagged with a sequence number which is originated by the destination node. Each station sends and updates its routing table periodically. The messages being flooded between stations show a list of accessible nodes and the number of stations needed to obtain that particular node. Routing information is broadcast periodically by broadcasting or multicasting the packets. Each mobile station in DSDV protocol must publish its data routing table to its neighboring nodes. As the information in the table may change frequently, the advertisement should be done on the continuous basis so that every station can locate its neighbors in the network. It ensures the shortest number of nodes (hops) required from source station to a destination station.

The information flooded by each node will contain its new sequence number parameter and the following information for each new route: the number of hops required to reach the destination, the new sequence number and the destination address.

\subsection{Opitmized Link State Routing (OLSR) Protocol}

OLSR protocol [22] is a pure link state protocol. Whenever there is any modification in the topology then information is flooded to all nodes. This causes overheads and such overheads are decreased by Multipoint relays (MPR). Two types of control messages are employed in OLSR; they are topology control and hello messages. There is also Multiple Interface Declaration (MID) packets which are employed for declaring other station that the declaring station can have several OLSR interface addresses [23]. The MID message is broadcasted throughout the network only by MPRs. Also there is a "Host and Network Association" (HNA) packet which gives the external routing data by providing the possibility for routing to the external addresses.

\section{SimUlation ENVIRONMENT 4.1. Mobility Model}

Mobility model describes changes in the stations velocity and acceleration over time and their movement. Basic parameters related to node movement are mobility speed, number of nodes, sending rate, pause time, number of connections, simulation duration. Mobility models can be categorized in two types group and entity models. The motions of mobile stations in entity models are independent from each other, but in group models the movements of stations are dependent on each other [24].

In our article we chose the Random Waypoint Mobility, generated by the software BonnMotion [25]. It is an entity model. A station in this model can select any random velocity and any random destination. The station begins moving towards the chosen destination station. After obtaining the destination station, the station stops for a small amount of time defined by the "Pause Time" attribute and again the station repeats the process until the simulation stops.

\subsection{Simulation Parameters}

We elaborate the experiments for the evaluation of the performance of ad hoc routing protocols AODV, DSR, DSDV, OLSR and DYMO with varying Number of Nodes. We have 30 simulations run in total out of which 30 trace files has been generated for Random Waypoint Mobility each. We studied all performance metrics in our simulation under varying Number of Nodes (20 to 70 Nodes) and while other attributes are fixed. Table 2 presents the simulation parameters adapted to our simulation. 
Table 2. Simulations parameters

\begin{tabular}{|l|l|}
\hline \hline Parameters & Value \\
\hline Simulator & NS-2.34 \\
\hline Data packet size & 512 byte \\
\hline Simulation duration & $50 \mathrm{sec}$ \\
\hline Environnement size & $500 \mathrm{~m} \times 500 \mathrm{~m}$ \\
\hline Number of Nodes & $20,30,40,50,60,70$ \\
\hline Pause Time & $5 \mathrm{sec}$ \\
\hline MAC Layer Protocol & IEEE 802.11 \\
\hline Traffic Type & CBR \\
\hline Number of connections & 15 \\
\hline Maximum Mobility & $20 \mathrm{~m} / \mathrm{s}$ \\
\hline Mobility Model & Random Waypoint \\
\hline Protocols & AODV, DSR, DSDV, OLSR, DYMO \\
\hline \hline
\end{tabular}

\subsection{NS-2 simulator}

The network simulations have been performed using network simulator NS-2. The NS-2 is software used to simulate discrete event for networks. It simulates events such as sending, receiving, dropping and forwarding packets. The ns-allinone-2.34 [4] integrates simulation for MANET routing protocols as AODV, DSR and DSDV. The simulation of protocols OLSR and DYMO are based on the work presented in [26]. NS-2 is implemented in C++ programming language with Object Tool Common Language.

Although NS-2. 34 can be implemented on different Operating Systems, for this article, we select a Linux platform i.e. Ubuntu LTS 12.04, as Linux provides development tools as AWK [27] that can be employed with the simulation. To run a NS-2.34 simulation, the user must write the OTCL simulation script. NS-2 gives a visual presentation of the network by tracing stations movements and events and writing them in a file named as Network Animator file (or NAM file) [4]. The performance parameters are graphically visualized in MATLAB [28].

\subsection{Performance Metrics}

RFC2501 [29] illustrates a number of quantitative metrics that can be used for evaluating the performance of MANET routing protocols. To analyze routing protocols (AODV, DSR, DSDV, OLSR and DYMO), we have focused on four performance metrics for evaluation which are Packet Delivery Ration, Average End to End Delay, Normalized Routing Load and Average Throughput.

\subsubsection{Packet Delivery Fraction}

Packet Delivery Fraction is defined as the ratio of number of received information packets successfully at the destinations statins over the number of information packets transmitted by the sources stations. Packet Loss Fraction is defined as 1-Packet Delivery Fraction.

\subsubsection{Average End to End Delay}

The Average End to end delay is the average time from the sending of a packet at a source station until packet delivery to a destination station. It contains all possible delays generated by queuing at the interface queue, retransmission delays, propagation, transfer times of data and packets buffering during route discovery process. 


\subsubsection{Normalized Routing Load}

The Normalized Routing Load is the ratio of all routing control packets send by all sources nodes to number of received data packets at the destination nodes.

\subsubsection{Average Throughput}

Average Throughput is defined as the average number of packets successfully obtained their destinations per unit time. This parameter is calculated as the number of bits delivered per second.

\section{Simulation ReSUlts AND ANALYSiS}

The results after simulation are viewed in five figures. The performance of routing protocols based on the varying the Number of Node is done on parameters like Packet Delivery Ratio, Average End to End Delay, Normalized Routing Load and Average Throughput.

\subsection{Packet Delivery Ratio}

From Figure 3, we note that DSDV protocol has the lowest Packet Delivery Ratio compared to other protocol (AODV, DSR, OLSR and DYMO). DSR and AODV demonstrate good performance (height Packet Delivery Ratio), but DSR is better than AODV. In comparing ondemand protocols, DSR shows the highest and DYMO the lowest Packet Delivery Ratio. As table-driven protocols, OLSR outperforms DSDV in terms of Packet Delivery Ratio.

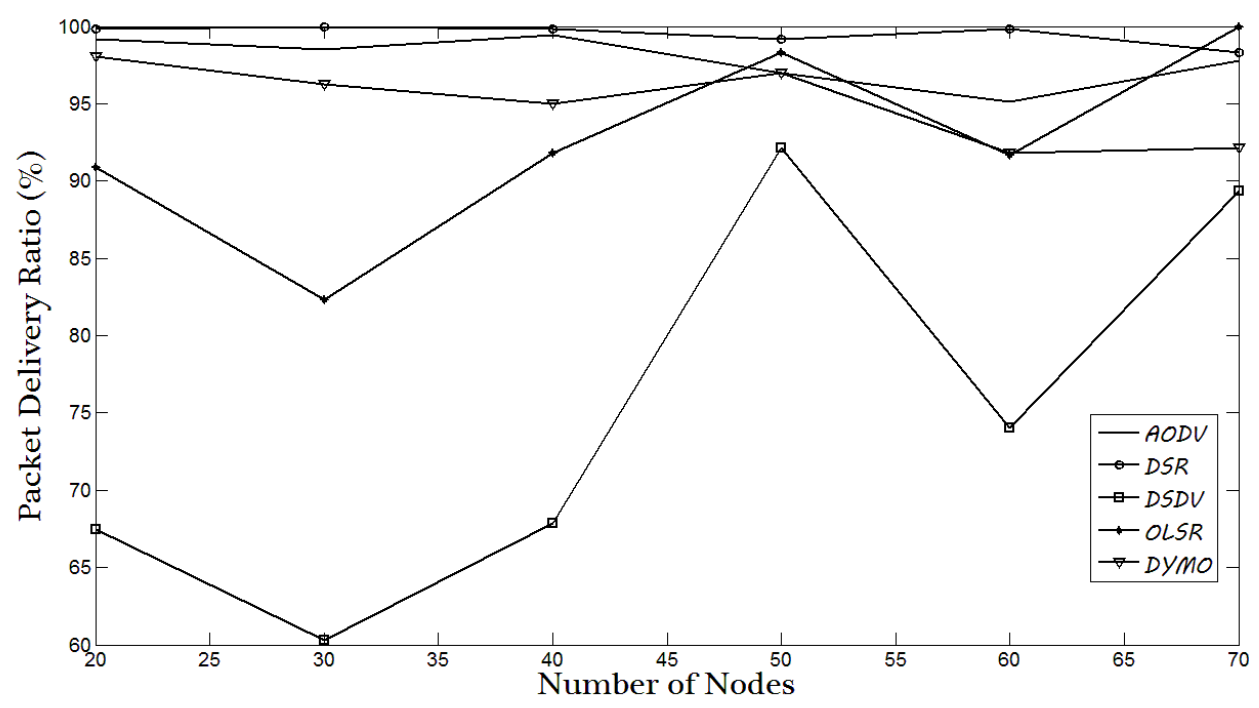

Figure 3: Packet Delivery Ratio versus Number of Nodes

\subsection{Average End to End Delay}

Figure 4 shows that AODV protocol has the highest value of Average End to End Delay (low performance) compared to other protocols. This figure does not precise the behavior of the protocols: DSR, DSDV, OLSR and DYMO. For this reason we elaborate the Figure 5. From this figure, the performance of DSR and DYMO as on-demand protocol are approximately the same. It seems as table-driven protocols have the lowest Average End to End Delay than on-demand protocols when we vary the Number of Nodes. OLSR and DSDV as table-driven protocols have 
routing tables and they do not need to discover the route for the same destination (low value of Average End to End Delay).

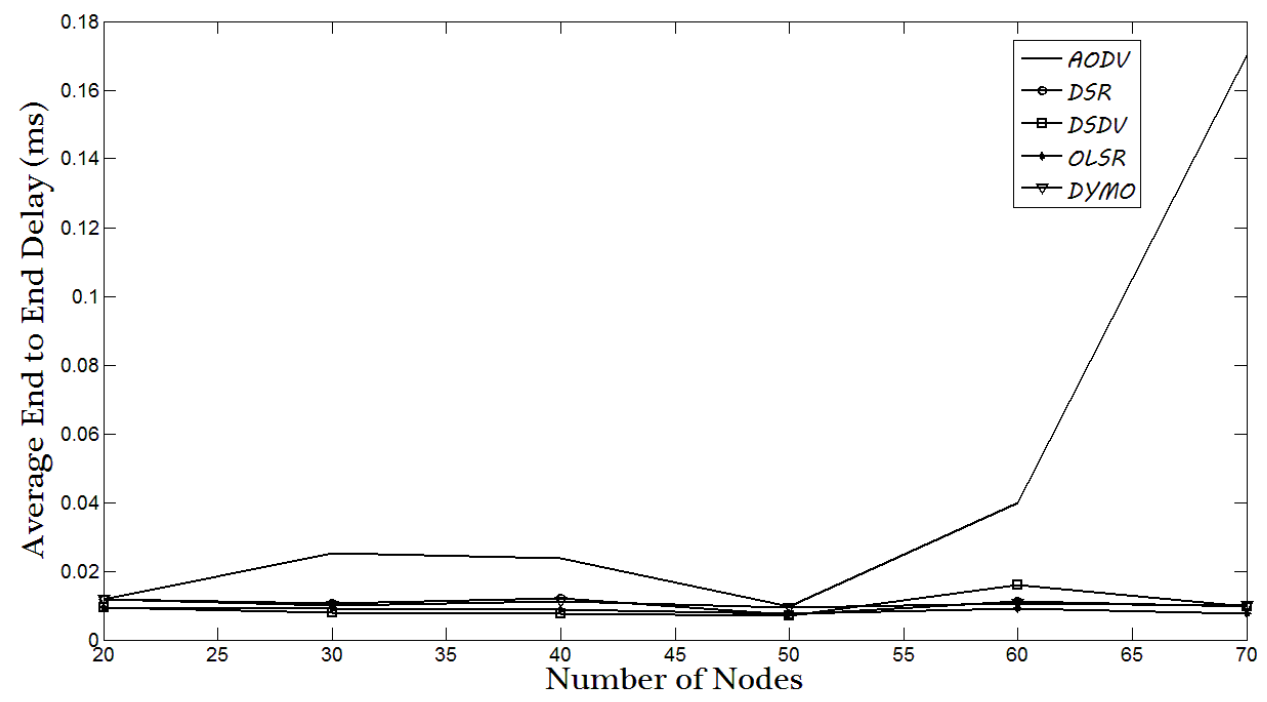

Figure 4: Average End of End Delay versus Number of Nodes

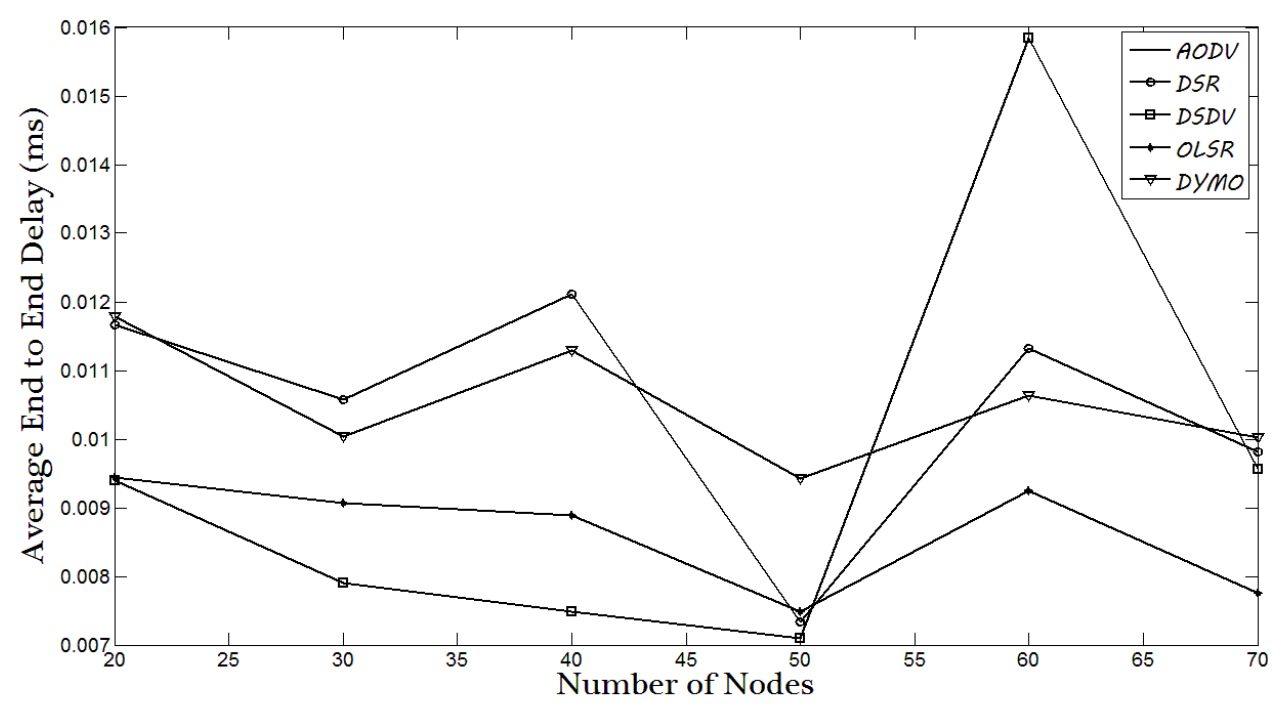

Figure 5: Average End of End Delay versus Number of Nodes

\subsection{Normalized Routing Load}

We remark from Figure 6 that when the Number of Nodes increase, the Normalized Routing Load increases. DSR has the lowest value of Normalized Routing Load (good performance) while the OLSR has the highest value (low performance). As driven-protocols, DSDV has better performance than OLSR in terms of Normalized Routing Load. By considering only on-demand protocols and the value of Normalized Routing Load observed, DSR outperforms other protocols (AODV and DYMO) and DYMO demonstrates the lowest performance. 


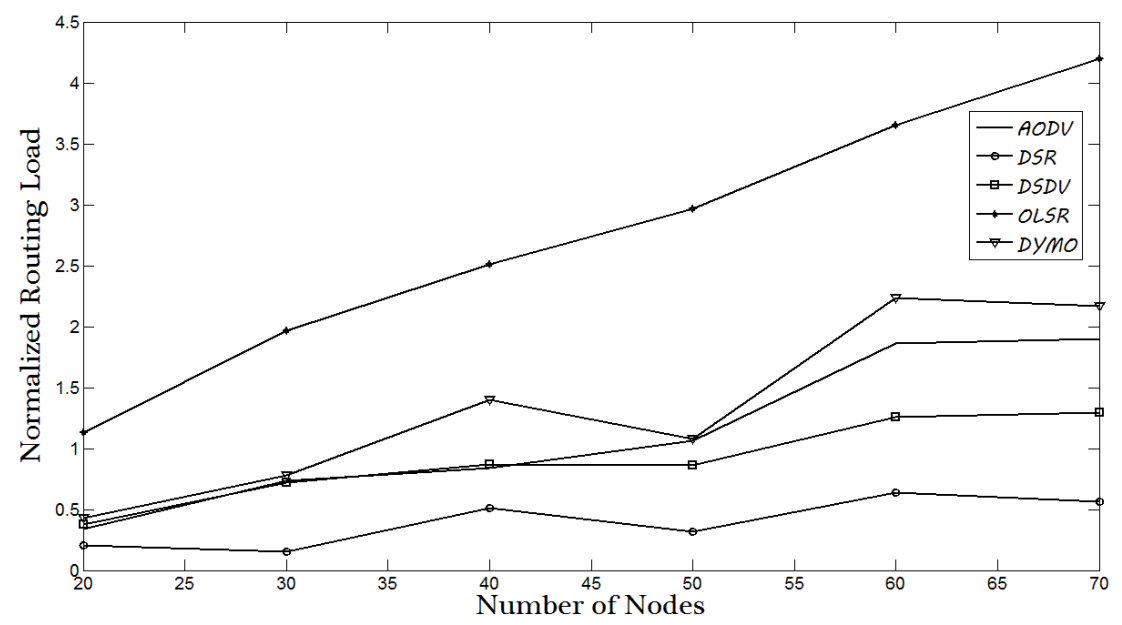

Figure 6: Normalized Routing Load versus Number of Nodes

\subsection{Average Throughput}

Figure 7 shows that DSDV demonstrates the lowest Average Throughput compared to other protocols (low performance). DSR and AODV give a good performance (highest value of Average Throughput). OLSR outperforms the other table-driven protocol DSDV in terms of Average Throughput. DYMO compared to the other on-demand protocols (AODV and DSR) has the lowest value of Average Throughput (low performance).

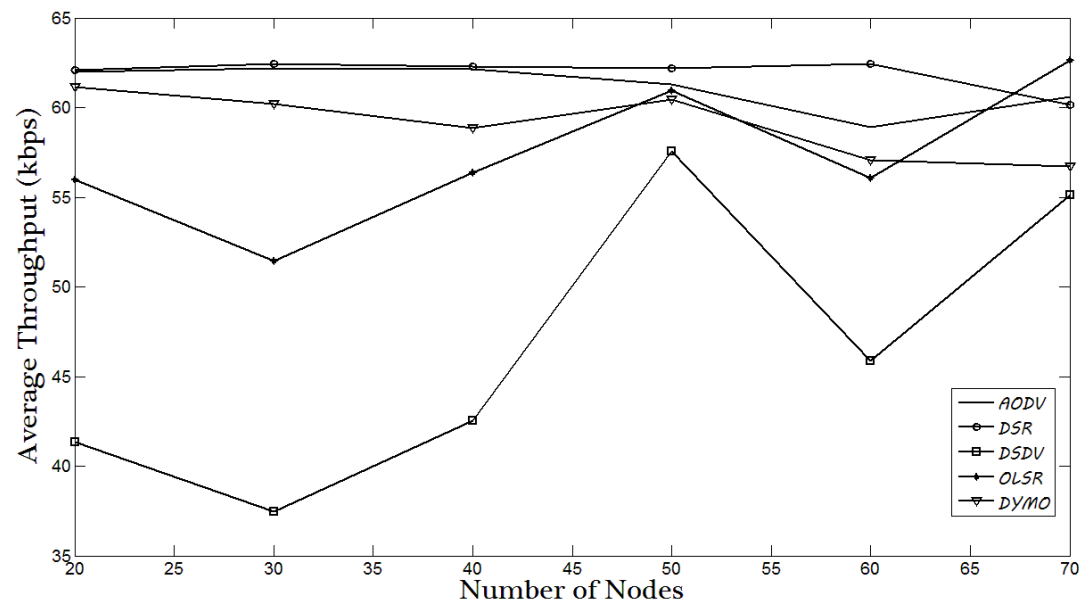

Figure 7: Average Throughput versus Number of Nodes

\section{Conclusions}

We study in this article several MANET routing protocols such as AODV, DSR, DSDV, OLSR and DYMO. With the help of NS-2 simulation we compared these protocols under different network conditions. By varying Number of Nodes, We measure Average Throughput, the Packet Delivery Ratio, Normalised Routing Load and Average End to End Delay as performance matrices.

In terms of Packet Delivery Ratio, AODV, DSR have higher value than other protocols (DSDV, OLSR and DYMO). As table-driven protocols, DSDV and OLSR show the lowest Average End 
to End Delay (good performance) compared to on-demand protocols (AODV, DSR and DYMO). DSR demonstrates the lowest Normalised Routing Load than other protocols. In almost all scenarios, AODV and DSR outperform other protocols (DSDV, OLSR and DYMO) in terms of Average Throughput.

Our focus in the future work is to extend the set of the experiments by taking into consideration other simulations parameters (propagation models, MAC protocols, etc.). Our future simulation will be elaborated in NS-3[30]

\section{REFERENCES}

[1] Rahman A, Islam S, Talevski A., "Performance measurement of various routing protocols in adhoc network", In: Proceedings of the international multiconference of engineers and computer scientists, vol. 1. Hong Kong: IMECS; 2009.

[2] Tyagi SS, Chauhan RK., "Performance analysis of proactive and reactive routing protocols for ad hoc networks", Int J Comput Appl 2010;1(14).

[3] Basagni S, Conti M, Giordano S, Stojmenovic I., "Mobile ad hoc networking", A John wiley and sons, Inc., Publication; 2004.

[4] NS -2, the ns Manual, Available at http: //www. isi.edu/nsnam/ns/doc.

[5] AkshaiAggarwal, SavitaGandhi, NirbhayChaubey, "Performance Analysis of AODV, DSDV and DSR in MANETs", IJDPS, Vol.2, No.6,. November 2011.

[6] P. Manickam T. Guru Baskar, M.Girija, Dr.D.Manimegala, "Performance Comparisons of Routing Protocols in Mobile Ad Hoc Networks", International Journal of Wireless \& Mobile Networks (IJWMN), pp. 98-106, February 2011.

[7] Sabina Barakovic, Suad Kasapovic, Jasmina Barakovic, "Comparison of MANET Routing Protocols in Different Traffic and Mobility Models", Telfor Journal, Vol. 2, No. 1, 2010.

[8] Guntupalli Lakshmikant, A Gaiwak, P.D. Vyavahare, "Simulation Based Comparative Performance Analysis of Adhoc Routing Protocols", In proceedings of TENCON 2008.

[9] Chenna Reddy, P.; ChandraSekhar Reddy, P., "Performance Analysis of Adhoc Network Routing Protocols”, ISAUHC'06, International Symposium on Ad Hoc andUbiquitous Computing, vol., no., pp.186-187, 20-23 Dec. 2006.

[10] Kapang Lego, Pranav Kumar Singh, Dipankar Sutradhar, "Comparative Study of Adhoc Routing Protocol AODV, DSR and DSDV in Mobile Adhoc NETwork", Indian Journal of Computer Science and Engineering Vol. 1 No. 4 364-371, 2011.

[11] Ginni Tonk, Indu Kashyap, S.S. Tyagi, "Performance Comparison of Ad-Hoc Network Routing Protocols using NS-2”, International Journal of Innovative Technology and Exploring Engineering (IJITEE)ISSN: 2278-3075, Volume- 1, Issue-1, June 2012.

[12] Li Layuan, Li Chunlin, Yaun Peiyan, "Performance evaluation and simulation of routing protocols in ad hocnetworks", Computer Communications 30 (2007) 1890- 1898.

[13] Vijayalaskhmi M. Avinash Patel, Linganagouda Kulkarni, "QoS Parameter Analysis on AODV and DSDV Protocols in a Wireless Network", International Journal of Communication Network and Security, Volume-1, Issue-1, 2011.

[14] Deepak Kumar, Ashutosh Srivastava, S C Gupta, "Performance Comparison of DSDV and AODV Routing Protocols in MANETS", International Journal of Electronics Communication and Computer Technology (IJECCT) Volume 2 Issue 3, May 2012.

[15] Jun-Zhao Sun, "Mobile Ad Hoc Networking: An Essential Technology for Pervasive Computing”, Proceedings of International conference on info-tech and info-net, Vol-3, pp. 316-321, 2001. 
[16] C.E. Perkins and E.M. Royer, “Ad-hoc On-Demand Distance Vector Routing”, Proceeding of 2nd IEEE Workshop, Mobile Computing System Applications, pp:90-100, 1999

[17] Perkins, E. Belding-Royer, and S. Das, "Ad hoc On-Demand Distance Vector (AODV) Routing, "draft-ietf-manet-aodv-13.txt, Feb. 2003

[18] S. A. Ade1\& P.A.Tijare, "Performance Comparison of AODV, DSDV, OLSR and DSR Routing Protocols in Mobile Ad Hoc Networks", International Journal of Information Technology and Knowledge Management July-December 2010, Volume 2, No. 2, pp. 545-548.

[19] J. Broch, D. Jhonson, and D. Maltz, "The dynamic source routing protocol for mobile adhoc networks for IPv4”, IETF RFC 4728, Feb 2007

[20] I. Chakeres and C. Perkins, "Dynamic MANET On-Demand (DYMO) Routing”, IETF InternetDraft, draft-ietf-manet-dymo-23, Oct. 2012

[21] Charles E. Perkins and Pravin Bhagwat, "Highly dynamic destination-sequenced distance-vector routing (DSDV) for mobile computers", Technical report, IBM Research and University of Maryland, USA, 1994.

[22] T. Clausen and P. Jacquet, "Optimized link State Routing protocol (OLSR)", RFC-3626, IETF Networking Group, 2003.

[23] Aleksandr Huhtonen, "Comparing AODV and OLSR routing protocols", Helsinki University of Technology, Telecommunication software and multimedia laboratory, 2004.

[24] Valentina Timcenko, Mirjana Stojanovic, Slavica Bostjancic Rakas (2009), "MANET Routing Protocols vs. Mobility Models: Performance Analysis and Comparison", Proceedings of the 9th WSEAS International Conference on Applied Informatics and Communications (AIC '09).

[25] BonnMotion: A mobility scenario generation and analysis tool, Available at http://sys.cs.uos.de/bonnmotion/

[26] http://masimum.inf.um.es/fjrm/development/

[27] Robins A.D, “GAWK: an effective AWK programming”, 3rd ed, April 2010.

[28] MATLAB: The language of Technical Computing, Available at http://www.mathworks.com/

[29] S.Corson and J.Macker, "Routing Protocol Performance Issues and Evaluation considerations", RFC2501, IETF Network Working Group, January 1999.

[30] The NS-3 reference manual, Available at http://www.nsnam.org/

\begin{abstract}
Authors
Mohamed elboukhari received the DESA (diploma of high study) degree in numerical analysis, computer science and treatment of signal in 2005 from the University of Science, Oujda, Morocco. He is currently an assistant professor, department of Applied Engineering, ESTO, university Mohamed First, Oujda, Morocco. His research interests include cryptography, quantum cryptography and wireless network security, Mobile Ad Hoc Networks (MANETS).

Mostafa azizi received the diploma of engineer in automatic and computer industry in 1993 from school Mohammadia of engineers, Rabat, Morocco and he received the $\mathrm{Ph}$. D in computer science in 2001 from the university Montreal, Canada. He is currently professor at university of Mohamed first, Oujda, Morocco. His main interests include aspect of real time, embedded system, security and communication and management of the computer systems in relation with process industry.

Abdelmalek azizi received the $\mathrm{Ph} . \mathrm{D}$ in theory of numbers in 1993 from university Laval, Canada. He is professor at department of mathematics in university Mohamed First, Oujda, Morocco. He is interesting in history of mathematics in Morocco and in the application of the theory of number in cryptography.
\end{abstract}

